\title{
Volatile Characterization by Multivariate Optimization of Headspace-Solid Phase Microextraction and Sensorial Evaluation of Chardonnay Base Wines
}

\author{
Juliane E. Welke, ${ }^{a, b}$ Mauro Zanus, ${ }^{c}$ Marcelo Lazarotto, ${ }^{c}$ \\ Karine G. Schmitt ${ }^{a}$ and Claudia A. Zini ${ }^{*, a}$ \\ anstituto de Química, Universidade Federal do Rio Grande do Sul, \\ Avenida Bento Gonçalves, 9500, 91501-970 Porto Alegre-RS, Brazil \\ ${ }^{b}$ Instituto Federal de Educação, Ciência e Tecnologia Farroupilha, \\ Rua Erechim, 860, 98280-000 Panambi-RS, Brazil \\ 'Empresa Brasileira de Pesquisa Agropecuária, Embrapa Uva e Vinho, \\ Rua Livramento, 515, 95700-000 Bento Gonçalves-RS, Brazil
}

\begin{abstract}
Pouco é conhecido sobre o aroma dos vinhos produzidos na região sul do Brasil, que é responsável por $90 \%$ da produção brasileira de vinho. Um método baseado na microextração em fase sólida no modo "headspace" (HS-SPME) foi desenvolvido para a extração de compostos voláteis e semivoláteis relacionados ao aroma de vinhos base, de cinco diferentes vinícolas do estado do Rio Grande do Sul (Brasil). A relação entre a composição volátil, qualidade aromática e avaliação sensorial dos vinhos Chardonnay foi investigada neste estudo. As condições otimizadas do método de HS-SPME foram: utilização da fibra DVB-CAR-PDMS, $1 \mathrm{~mL}$ de amostra, 30\% de $\mathrm{NaCl}, 45$ min de extração a $55^{\circ} \mathrm{C}$, sem o uso de diluição e agitação da amostra. Dezoito compostos foram identificados e catorze foram tentativamente identificados. Os ésteres foram os compostos majoritários $(56 \%)$ e os outros compostos minoritários pertencem à classe dos álcoois e ácidos. Os vinhos do Vale dos Vinhedos e de Pinto Bandeira apresentaram a mais alta pontuação em relação aos parâmetros sensorais avaliados. Estes vinhos foram caracterizados por altas concentrações de ésteres etílicos, o que contribui para o aroma frutado dos vinhos.
\end{abstract}

Very little is known about the aroma of wines produced in the South part of Brazil, a region that is responsible for $90 \%$ of the Brazilian wine production. A headspace solid phase micro extraction (HS-SPME) method was developed for the extraction of volatile and semivolatile compounds related to the aroma of base wines of five different wineries of the state of Rio Grande do Sul (Brazil). The relationships among volatile composition, aroma quality and sensory evaluation of Chardonnay base wines were performed in this study. Optimum conditions for HS-SPME included use of DVB-CAR-PDMS coating, wine samples without further dilution, no stirring, sample volume of $1 \mathrm{~mL}, 30 \%$ of $\mathrm{NaCl}$, extraction time and temperature of $45 \mathrm{~min}$ and $55^{\circ} \mathrm{C}$, respectively. Eighteen compounds were identified and fourteen were tentatively identified in the samples. The majority $(56 \%)$ of them was esters and other minor components were alcohols and acids. The sensory analysis of Vale dos Vinhedos and Pinto Bandeira samples showed the highest quality scores, characterized by higher concentrations of ethyl esters, which contributes to the fruity aroma of these wines.

Keywords: flavour, sparkling wine, SPME, base wine, volatiles

\section{Introduction}

Aroma is one of the most important factors in determining wine character and quality. The compounds that define wine aroma are related to acceptance or rejection

*e-mail: cazini@iq.ufrgs.br of wines by the consumers. ${ }^{1,2}$ The aroma characteristics are the result of complex interactions among four factors: vineyard geographical site ${ }^{3}$ which is related to soil and climate characteristics, ${ }^{4}$ grape variety, ${ }^{2}$ yeast strain, ${ }^{5}$ and technical conditions of wine-making. ${ }^{6}$

Sparkling wines produced by traditional or Champenoise method entails double fermentation 
followed by aging of the wine in contact with the yeast in the bottle. The base wine is obtained from the first fermentation. After this step, a solution containing sugar and yeast is added to the base wine to provide proper conditions for the second fermentation. Therefore, the base wine can be considered as a decisive point for obtaining the best quality sparkling wines. Some of the major compounds that contribute to sparkling wine aroma are formed during the first fermentation, such as ethyl and acetate esters, which are mainly responsible for the floral and fruity wine aroma. ${ }^{5}$

The determination of aroma compounds is commonly performed by gas chromatography (GC). As the wine volatiles are found at levels ranging from ng $\mathrm{L}^{-1}$ to $\mathrm{mg} \mathrm{L}^{-1}$, sample preparation prior GC analysis is crucial. Headspace solid-phase microextraction (HS-SPME) is a solvent less technique in which sampling, extraction and concentration are integrated in one step, followed by sample introduction in an analytical instrument. ${ }^{7}$ Compared to traditional techniques, such as liquid-liquid extraction (LLE), SPME also offers other advantages such as simplicity, high sensitivity and reproducibility, requires low sample volume and can be automated. ${ }^{8}$ For this reason, it has been used for analysis of aroma volatiles in many food and beverages matrices. ${ }^{9}$

When utilizing SPME, method development needs to be conducted efficiently, mainly considering the type of fiber coating, sample volume and extraction conditions. ${ }^{10}$ The traditionally used univariate optimization design allows examining the effect of one variable at a time since all other variables are kept constant during an optimization experiment. Some univariate optimization studies have been conducted to determine the optimum analysis conditions for volatile extraction of wine by HS-SPME. ${ }^{10-12}$ However, this method might overlook the possibility of interactions among variables. Multivariate designs offer simultaneous variation of several parameters, consequently reducing the number of experiments to be performed in SPME optimization procedure. ${ }^{13-15}$ As to the knowledge of the authors, there is no published work about the utilization of multivariate optimization designs for SPME method development associated with the extraction of volatile and semivolatiles base wine aroma constituents.

Wines produced in the state of Rio Grande do Sul in the South part of Brazil represent $90 \%$ of the Brazilian wine production. The aroma of these wines are poorly known and for this reason this study was carried out to investigate the aroma of base wines of five different wineries of Rio Grande do Sul state, Brazil. The qualitative analysis of the wine headspace by HS-SPME was also related to the acceptance or rejection of these wines by consumers.

\section{Experimental}

\section{Samples, analytical reagents, and supplies}

The Chardonnay base wines were produced by five different wineries localized in places with latitude ranging between 28 and $29^{\circ}$ South: Flores da Cunha, Pinto Bandeira, Vale dos Vinhedos and Vacaria. These samples were provided in sealed bottles by Empresa Brasileira de Pesquisa Agropecuária (EMBRAPA) Uva e Vinho. The price range of wines obtained from different wineries was similar. Standard compounds: ethyl acetate, ethyl butanoate, ethyl propanoate, ethyl 2-methylbutanoate, ethyl isovalerate, ethyl hexanoate, ethyl lactate, ethyl octanoate, ethyl decanoate, diethyl succinate, diethyl hidroxybutanoate, propanol, hexanol, 2-phenylethanol, isoamyl acetate, phenylethyl acetate, hexanoic acid, octanoic acid, decanoic acid and dodecanoic acid were purchased from Aldrich (Steinheim, Germany). Individual stock solutions of each compound were prepared in ethanol purchased from Nuclear (São Paulo, Brazil). Model wine was prepared with (+)-tartaric acid $\left(6 \mathrm{~g} \mathrm{~L}^{-1}\right)$ supplied by Synth (São Paulo, Brazil) and $10 \%$ of ethanol in MilliQ deionised water. The $\mathrm{pH}$ was adjusted to 3.5 with sodium hydroxide (Nuclear, São Paulo, Brazil). In order to obtain a sample as close to the real wine matrix as possible, the stock standard solutions were diluted in model wine to perform the extraction of each standard compound by SPME to proceed with their identification. The SPME fibers were purchased from Supelco (Bellefonte, PA, USA): $7 \mu \mathrm{m}$ polydimethylsiloxane (PDMS) StableFlex, $100 \mu \mathrm{m}$ PDMS, $85 \mu \mathrm{m}$ PA, $60 \mu \mathrm{m}$ carbowax (polyethylene glycol) (CW(PEG)) metal, $85 \mu \mathrm{m}$ carboxenpolydimethylsiloxane (CAR/PDMS) StableFlex, $65 \mu \mathrm{m}$ polydimethylsiloxane-divinylbenzene (PDMS/ DVB) StableFlex and 50/30 divinylbenzenecarboxenpolydimethylsiloxane (DVB/CAR/PDMS) StableFlex. All fibers were conditioned according to the manufacture's recommendation prior to their first use. Sodium chloride of analytical grade was purchased from Nuclear (São Paulo, Brazil) and $n$-alkanes from Sigma-Aldrich (Milwaukee, WI, USA).

\section{Chromatographic conditions}

A Shimadzu gas chromatograph 17A coupled to a mass spectrometer detector QP 5050A (GC/MSD) and a Shimadzu gas chromatograph 17A with a flame ionization detector (GC-FID) were employed to perform all chromatographic analyses. Two capillary columns were used under the following conditions: 
(i) OV-5 (30 $\mathrm{m} \times 0.25 \mathrm{~mm} \times 0.25 \mu \mathrm{m})$ using initial oven temperature of $35^{\circ} \mathrm{C}$ for $5 \mathrm{~min}$ and three temperature ramps $\left(3{ }^{\circ} \mathrm{C} \min ^{-1}\right.$ until $120{ }^{\circ} \mathrm{C}, 5^{\circ} \mathrm{C}$ min $^{-1}$ until $200{ }^{\circ} \mathrm{C}$ and $10{ }^{\circ} \mathrm{C}$ min $^{-1}$ until $250{ }^{\circ} \mathrm{C}$, where it was held for $5 \mathrm{~min})$; (ii) Supelcowax $10(30 \mathrm{~m} \times 0.25 \mathrm{~mm} \times 0.25 \mu \mathrm{m})$ with the same temperature program, with the exception of final temperature, that was $220^{\circ} \mathrm{C}$. Injector and detector temperature were kept at $250^{\circ} \mathrm{C}$ for DB5 and at $220^{\circ} \mathrm{C}$ for Supelcowax 10, while helium flow rate was

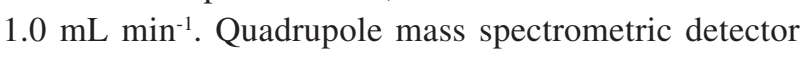
was operated in the electronic impact mode at $70 \mathrm{eV}$, and mass/charge range was 40 to 450 . Electron multiplier was at $1250 \mathrm{~V}$. Linear temperature programmed retention indices (LTPRI) of volatile compounds were calculated using the retention data of a $1 \%$ hexanic solution of $n$-alkanes (C9 to C24) and the retention data of the base wine volatile components. Several components were tentatively identified through comparison of their LTPRI with those registered in the literature databases (FFNSC: Flavor and Fragrance Natural and Synthetic Compounds library, Shimadzu, Milan, Italy). Mass spectra of volatile compounds were also compared with the ones stored in the 6th edition Wiley mass spectra library in order to complete the process of tentative identification of compounds. Whenever standard compounds were available, coinjection was performed in order to positively identify the wine volatile compounds. Semiquantitative data were calculated from the GC peak areas and were expressed as relative percentage (peak area \%) of the total volatile constituents.

\section{Experimental conditions}

Initially, some experiments were performed in order to check the best coating for HS-SPME, the more convenient dilution for wine samples, and the influence of magnetic stirring. During these experiments, extraction time was $30 \mathrm{~min}$ at $60^{\circ} \mathrm{C}$, and $5 \mathrm{~mL}$ of base wine were employed in $10 \mathrm{~mL}$ vials. For fiber screening, six commercially available SPME coatings were tested, as listed above, in order to choose the most appropriate fiber for these experiments. In order to find the appropriate concentration of ethanol in the samples, base wines were analyzed without dilution (10\% v/v ethanol content) and were diluted with water until ethanol content of 5\% (v/v) and $2 \%(\mathrm{v} / \mathrm{v})$. In a further step, multivariate design was performed, and the parameters optimized were extraction time, temperature during extraction, ion strength and sample volume. The initial screening design was performed using a $2^{4-1}$ factorial. Desorption time was $5 \mathrm{~min}$ and no memory effect was observed between chromatographic runs.

\section{Sensory analysis}

The wines were evaluated by a panel of expert panelists from Embrapa Uva e Vinho. The evaluation of beverages by sensory analysis was done using quantitative descriptive analysis (QDA) methodology. ${ }^{16}$ Wines were tasted immediately after opening the bottles. The wine tasters indicated different perceived descriptors which include visual, olfactory and gustative assessment. The intensity of each attribute was rated on a scale from 0 to 5 , where: 0 indicated that the descriptor was not perceived, $1=$ very low, $2=$ low, $3=$ middle, $4=$ high and $5=$ very high intensity. The panelists were also asked to rate the global sensory quality considering the organoleptic perception. During the experiment each taster kept his/her opinion and score sheets confidential from the other tasters. Mineral water was provided for mouth rising between each trial of wine quality. Wines were served in same type and shape of glasses. The scores obtained for each sample were analyzed by analysis of variance (ANOVA), followed by least significant difference (LSD) test. Differences were considered significant at $\mathrm{p}<0.05$.

Hierarchical cluster analysis

Semiquantitative results were processed with STATISTICA for Windows program package (version 7.1, Statsoft, Tulsa, Oklahoma, USA, 2005). Similarities among samples were found out using Euclidean distance and the Ward method and results are presented as a dendogram. ${ }^{17}$

\section{Results and Discussion}

\section{SPME fiber coating screening}

The sensitivity of SPME extraction technique depends greatly on the value of the distribution constant of analytes partitioned between the sample and fiber coating material. For this reason, the extraction efficiency of six SPME fiber coatings was tested, according to Experimental section, in order to find which coating would have the highest affinity toward volatiles and semivolatiles wine constituents. The total area of the chromatographic peaks and the number of chromatographic peaks were used to identify the most appropriate SPME coating for the extraction of wine volatiles. The coatings PDMS-DVB, CAR-PDMS and DVB-CAR-PDMS showed the best performance; however, using the triple phase DVB-CAR-PDMS coating, it was possible to achieve the highest number of chromatographic peaks and chromatographic area (Figure 1). Similar outcomes were reported formerly for SPME extraction of 
volatiles from ice wine and table wine. ${ }^{5,18}$ Its higher efficiency may be due to its triple film, which provides three distinct coatings, lending to it an intermediate polarity. The divinyl benzene (DVB) layer retains less volatile analytes, allowing the diffusion of the smaller and more polar ones to the carboxen (CAR) layer. Extraction occurs basically through adsorption and is recommended for volatile and semivolatile compounds containing 3 to 20 carbons, covering a broad range of polarity. ${ }^{19}$ The DVB-CAR-PDMS fiber was utilized in all further optimization experiments of this work.
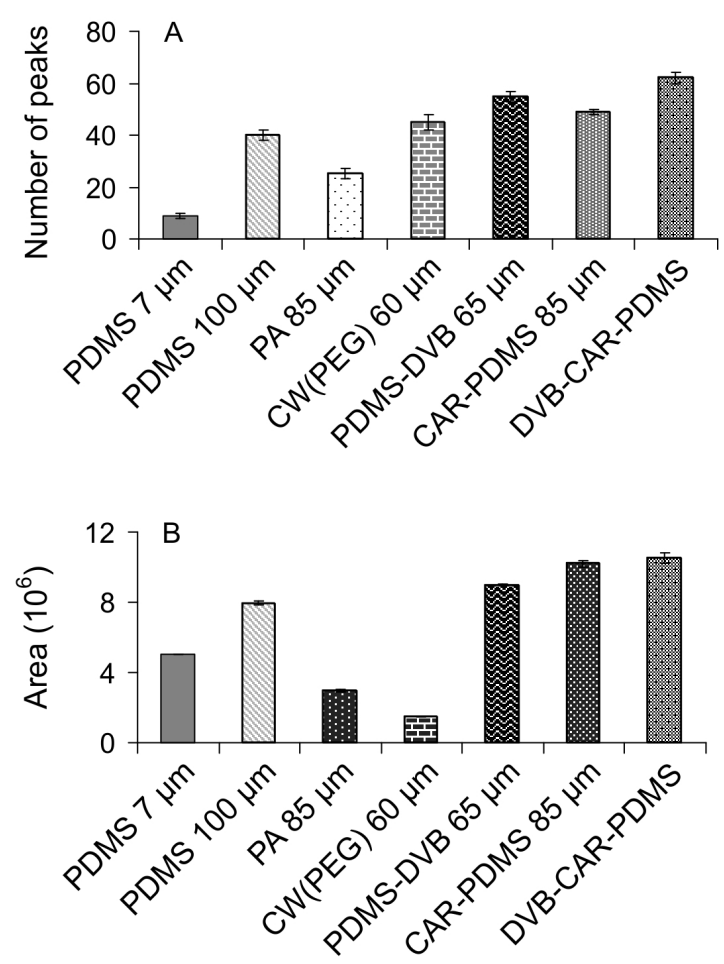

Figure 1. Comparison of the extraction efficiency of wine volatiles by HS-SPME with different coatings. The extraction was done during 30 min at $60{ }^{\circ} \mathrm{C}$ with $5 \mathrm{~mL}$ of base wine in $10 \mathrm{~mL}$ vials and the results of efficiency were expressed by (A) number of peaks and (B) total chromatographic peak area.

\section{Effect of ethanol concentration on extraction efficiency}

Ethanol is a major volatile compound in wine samples and is extracted by the coating. Rodriguez-Bencomo et $a l .{ }^{20}$ observed that chromatographic areas of volatile compounds of synthetic wine decreased as ethanol content increased in the range of $9-15 \%(\mathrm{v} / \mathrm{v})$. As ethanol is present in higher amounts, its massive sorption by the coating may impart a change in the coating nature and this may decrease the amount of compounds sorbed by the coating. Another hypothesis is that it may compete with other components of the sample for the active sites of the fiber and may also cause displacement of other volatiles during the adsorption step. ${ }^{17}$ In a study related to raw spirits,
Plutowska and Wardencki ${ }^{25}$ concluded that $20 \%$ of ethanol (v/v) gave the best performance for HS-SPME extraction. Therefore, it is important to consider the ethanol content in volatile determination of wines. In our work, we chose to investigate wine solutions where ethanol ranged from $2-10 \% \mathrm{v} / \mathrm{v}$, as typical ethanol percent in wine is $10 \% \mathrm{v} / \mathrm{v}$. A dilution effect is observed, when using smaller amounts of ethanol, resulting in lower extraction yields (Table 1). Similar results were reported for extraction of volatiles in raw spirits. ${ }^{18}$ In view of these results, no dilution of samples was done to lower ethanol content in all further optimization experiments.

Table 1. Effect of ethanol content on extraction of wine volatiles by HS-SPME using DVB-CAR-PDMS fiber, expressed as number of peaks and total area

\begin{tabular}{lccc}
\hline $\begin{array}{l}\text { Ethanol } \\
\text { content / \% }\end{array}$ & $\begin{array}{l}\text { Number } \\
\text { of peaks }\end{array}$ & Total area & RSD / \%* \\
\hline 10 & 47 & 7976349 & 6.5 \\
5 & 45 & 5750984 & 7.2 \\
2 & 43 & 3473650 & 3.2 \\
\hline *Relative standard deviation &
\end{tabular}

*Relative standard deviation.

\section{Effect of sample agitation on extraction efficiency}

Extraction efficiency is dependent on the distribution of the analyte between the sample matrix and the coating. The stirring enhances analyte transfer to the coating, thus reducing extraction time. Although the equilibration time is inversely related to agitation rate, the excessive agitation may adversely affect equilibration time and precision. ${ }^{8}$ In this work, when sample agitation was used, the number of peaks was $62 \pm 4$ and the total area was $4844844 \pm 4567$. Without sample agitation, the number of peaks was higher $(69 \pm 2)$, however the total area was lower $4362091 \pm 3984$. Student's t test was performed to determine significant differences between extraction with and without sample agitation. The use of magnetic stirring did not represent any improvement in the extraction yield at significance level of $p=0.05$ when total area was considered $(p=0.001)$. However, when number of peaks was considered, a significant difference between the tests (with and without agitation) was observed ( $\mathrm{p}=0.15)$. When sample stirring was employed, ethanol area increased and the number of peaks of other volatile compounds decreased. Further experiments were performed without agitation.

\section{Screening by a $2^{4-1}$ factorial design}

The variables evaluated in a $2^{4-1}$ factorial design were sample volume, extraction time, temperature and $\mathrm{NaCl}$ 
content. Some authors have found that the volume of HS in the vial should be minimized in order to increase the extraction efficiency. ${ }^{9-17}$ The extraction time depends on chemical nature of the target compounds and polymeric phase. The influence of extraction temperature has been studied by Mestres et al. ${ }^{21}\left(30,45\right.$ and $60{ }^{\circ} \mathrm{C}$ ) and a decrease in chromatographic peak area was observed with temperature increase. On the other side, Whiton and Zoecklein ${ }^{22}$ investigated how quantification can be influenced by sample matrix and sampling conditions. Tests with model solutions containing a range of typical wine volatiles demonstrated that increasing temperature and sampling time can enhance sensitivity for higher boiling point polar compounds but may diminish sensitivity for very volatile compounds. ${ }^{22}$ Moreover, Câmara et al. ${ }^{23}$ observed that the effect of temperature is not the same for several terpene compounds. High temperatures are supposed to release more analytes into the headspace, allowing better extraction with increasing temperature due to the enhanced mass transfer (kinetics). However they can adversely affect the absorption of analytes by the coating due to thermodynamic reasons (decrease of partition coefficients) and the extraction by the fiber coating decreases as the temperature rises..$^{23}$ Even though higher temperatures present a detrimental effect in partition coefficients and may eventually induce chemical changes for some typical analytes of food and beverage, no significant influence of higher temperatures was observed on both regards in this study. On the contrary, a positive influence of extraction temperature mainly on the amount of less volatile compounds extracted was observed when higher temperatures were used, according to former reports in the literature. ${ }^{12,24}$ Time and temperature are parameters closely related to each other, as an increase in temperature enables shorter exposure times, thus accelerating the analysis time..$^{20}$ The addition of an inorganic salt can change, within a certain range, the value of the partition coefficient of the analytes between the gas phase and sample matrix. A salting out effect occurs due to enhancement of ionic strength and a decrease in the solubility of the compounds in the liquid phase. ${ }^{9}$ Variables presenting the greatest influence on the experimental responses were verified applying a $2^{4-1}$ factorial design. Data used in the factorial design where the number of chromatographic peaks and the total chromatographic peak area. Table 2 lists the levels employed in these experiments. The data obtained were evaluated by analysis of variance (ANOVA) at $5 \%$ of significance level in order to assess whether the experimental variables were significantly affecting the performance of HS-SPME procedure. The results obtained by screening factorial design are summarized in the Pareto's chart in Figure 2. Considering number of chromatographic peaks as a response, the significant variables at $5 \%$ of significance level were time, temperature, $\mathrm{NaCl}$ content and the interaction between temperature and extraction time.

Table 2. Experimental levels employed for factorial screening design $\left(2^{4-1}\right)$ for optimization of wine volatiles extraction through HS-SPME

\begin{tabular}{lccc}
\hline \multirow{2}{*}{ Variable } & \multicolumn{3}{c}{ Coded variable } \\
\cline { 2 - 4 } & $(-1)$ & $(0)$ & $(-1)$ \\
\hline Temperature $/{ }^{\circ} \mathrm{C}$ & 30 & 45 & 60 \\
time / min & 10 & 35 & 60 \\
NaCl content / \% & 0 & 15 & 30 \\
Sample volume / $\mathrm{mL}$ & 1 & 3 & 5 \\
\hline
\end{tabular}
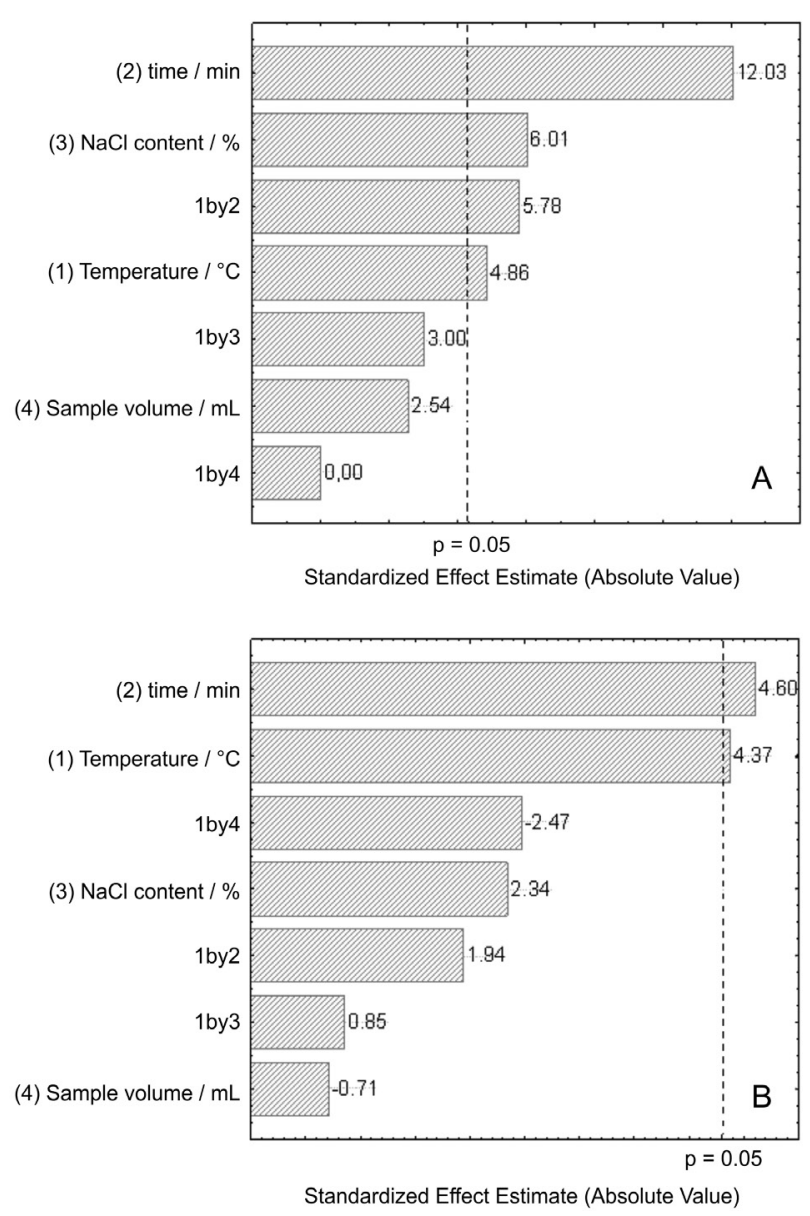

Figure 2. Pareto chart of effects and interactions of extraction conditions of wine volatiles by HS-SPME obtained using $2^{4-1}$ factorial design expressed by (A) number of peaks and (B) total chromatographic peak area. "pbyq" designates the effect of the interaction of variables $p$ and $q$.

Focusing on total chromatographic area, the significant variables were time and temperature of extraction. Furthermore, the results summarized in the Pareto chart indicate that increasing these three factors (time, temperature and $\mathrm{NaCl}$ content) will increase the analytical signal as well. 
Optimization of optimal extraction conditions by central composite design

A central composite design (CCD) was chosen to determine the optimal extraction conditions of influential factors in order to build the response surface models (Table 3). Five replicates were performed in the central point to estimate experimental error and to detect lack of fit. Temperature, time and $\mathrm{NaCl}$ concentration were used

Table 3. Experimental conditions of central composite design used for optimization of extraction conditions of wine volatiles through HS-SPME

\begin{tabular}{lccccc}
\hline \multirow{2}{*}{ Variable } & \multicolumn{5}{c}{ Coded variable } \\
\cline { 2 - 6 } & $(-1.68)$ & $(-1)$ & $(0)$ & $(1)$ & $(1.68)$ \\
\hline Temperature $/{ }^{\circ} \mathrm{C}$ & 33 & 40 & 50 & 60 & 67 \\
time / min & 43 & 50 & 60 & 70 & 77 \\
$\mathrm{NaCl}$ content $/ \%$ & 22 & 25 & 30 & 35 & 38 \\
\hline
\end{tabular}

in $\mathrm{CCD}$ and the experiments were carried out keeping the sample volume at $1 \mathrm{~mL}$. Response surface obtained by CCD is illustrated in Figure 3. The estimated optimum values for time, temperature and $\mathrm{NaCl}$ concentration were $45 \mathrm{~min}$, $55^{\circ} \mathrm{C}$ and $30 \%$ of $\mathrm{NaCl}$, respectively.

To evaluate the accuracy of the results obtained by response surface model, four experiments were carried out under optimal conditions. As can be seen in Table 4, there is a good agreement between calculated and experimental responses.

Volatile and semi-volatile compounds of Chardonnay base wines

The resulting optimized HS-SPME-GC/MSD method was applied to the analysis of wine samples (Figure 4). The volatile composition and the LTPRI values are shown in Table 5. Eighteen compounds were identified and fourteen

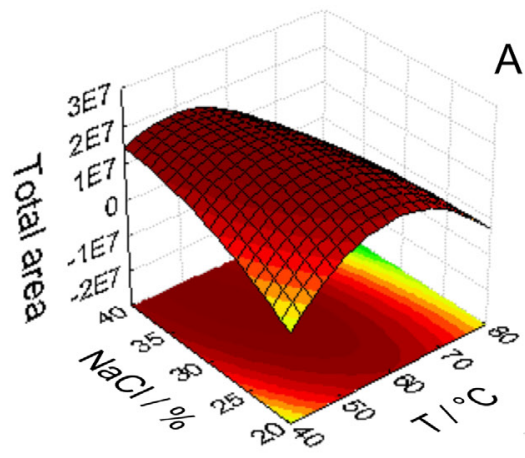

A

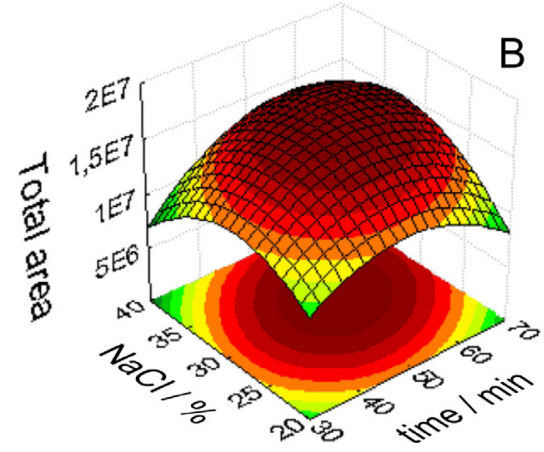

B
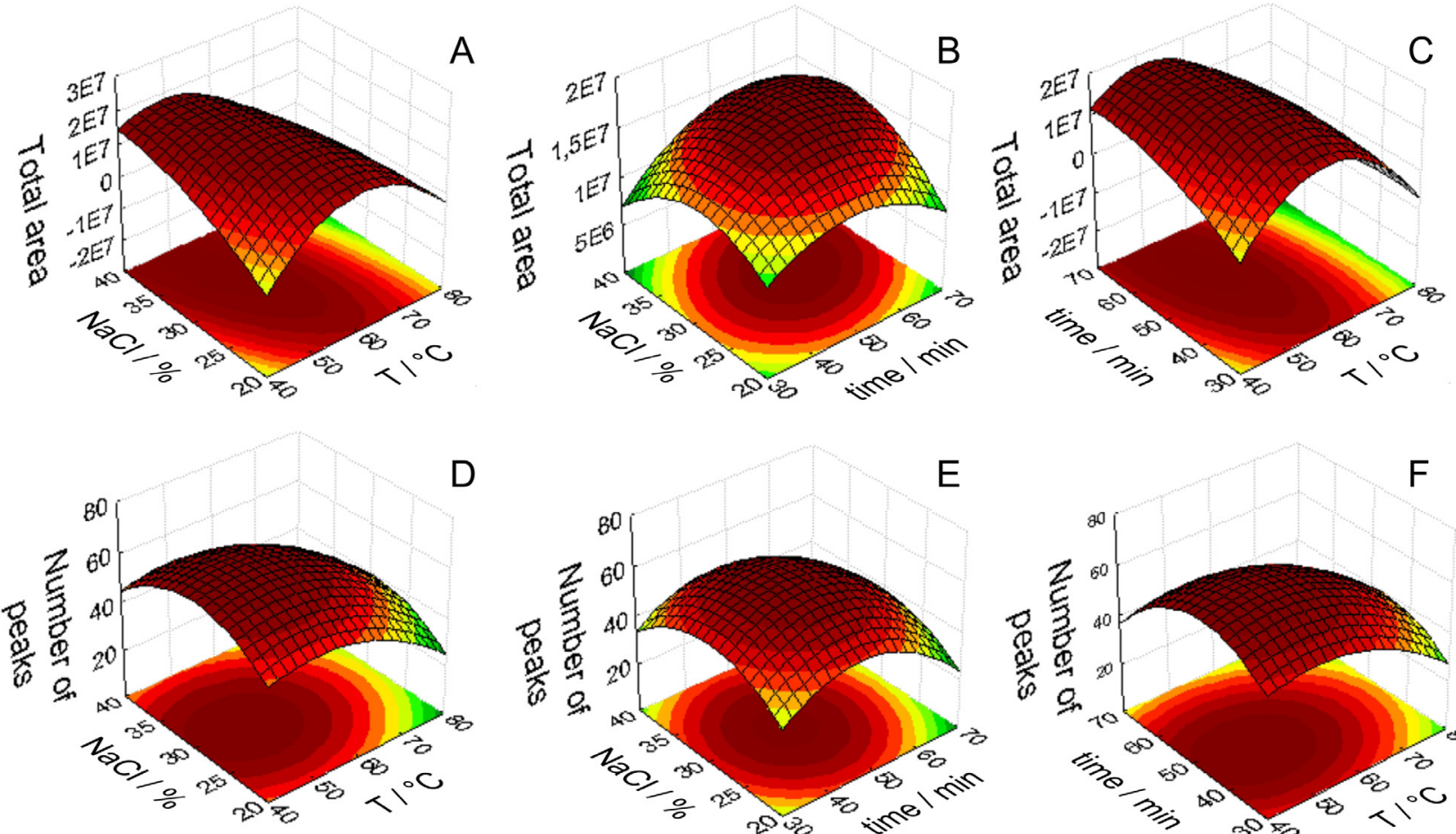

D

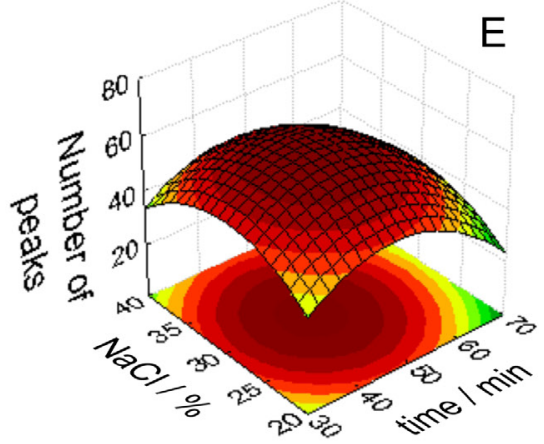

C

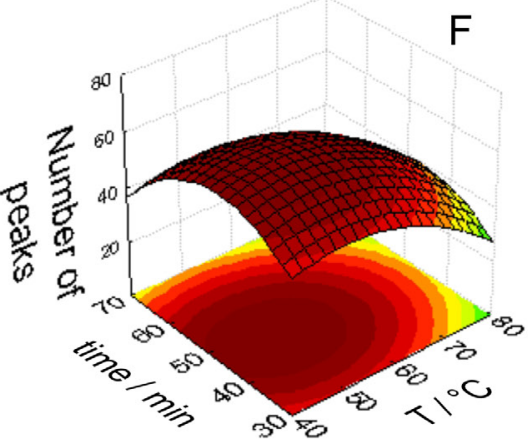

Figure 3. Response surface models obtained by central composite design for (A) total chromatographic peak area $v s$. NaCl content (\%) and extraction temperature $\left({ }^{\circ} \mathrm{C}\right)$, (B) total chromatographic peak area $v s . \mathrm{NaCl}$ content $(\%)$ and extraction time (min), (C) total chromatographic peak area $v s$. extraction time (min) and extraction temperature $\left({ }^{\circ} \mathrm{C}\right)$, (D) number of peaks $v s . \mathrm{NaCl}$ content $(\%)$ and extraction temperature $\left({ }^{\circ} \mathrm{C}\right),(\mathrm{E})$ number of peaks vs. $\mathrm{NaCl}$ content $(\%)$ and extraction time $(\mathrm{min}),(\mathrm{F})$ number of peaks $v s$. extraction time $(\mathrm{min})$ and extraction temperature $\left({ }^{\circ} \mathrm{C}\right)$.

Table 4. Comparison between calculated and experimental conditions obtained by CCD for extraction of wine volatiles

\begin{tabular}{ccccccc}
\hline Sample volume & Temperature & time & NaCl content & Optimum response & $\begin{array}{c}\text { Experimental } \\
\text { response }\end{array}$ \\
\hline $1 \mathrm{~mL}$ & $55^{\circ} \mathrm{C}$ & $45 \mathrm{~min}$ & $30 \%$ & 64 & 66 & N. of peaks \\
& & & & 17972500 & $18087308 \quad$ Total area \\
\hline
\end{tabular}




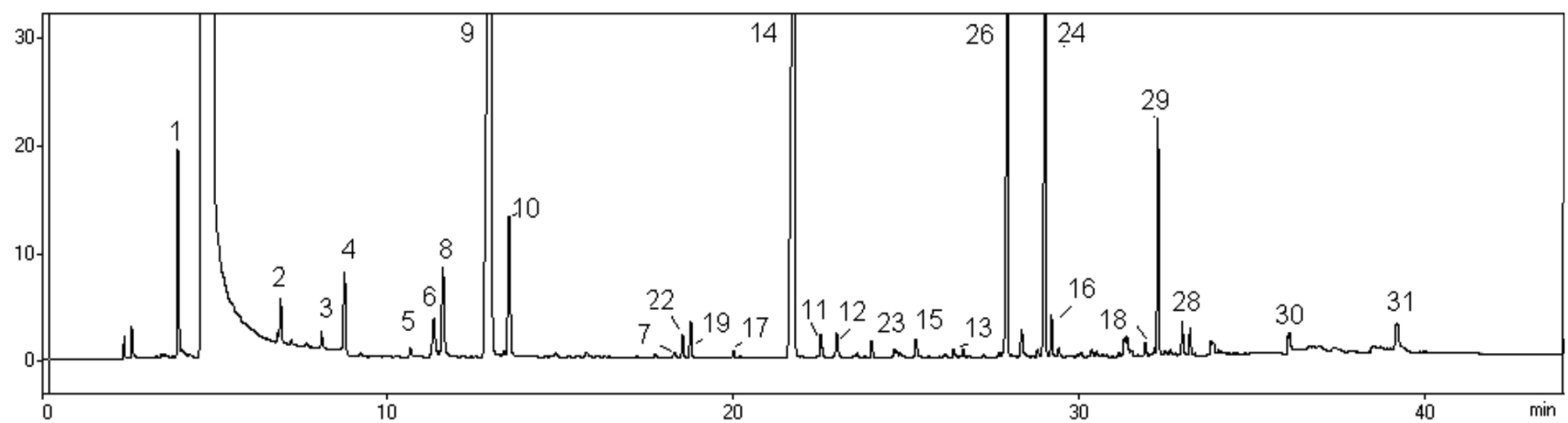

Figure 4.Total ion current chromatogram for HS-SPME-GC/MSD analysis of a typical base wine from Serra Gaúcha. Peaks numbers are related to Table 5.

Table 5. Volatiles compounds tentatively identified in base wines

\begin{tabular}{|c|c|c|c|c|c|c|c|c|c|c|}
\hline & \multirow{2}{*}{ Compound } & \multirow{2}{*}{ LTPRI OV5 } & \multirow{2}{*}{$\begin{array}{l}\text { LTPRI } \\
\text { FFNSC }\end{array}$} & \multirow{2}{*}{$\begin{array}{l}\text { LTPRI } \\
\text { Wax }\end{array}$} & \multirow{2}{*}{$\begin{array}{c}\text { LTPRI } \\
\text { Lit [Reference] }\end{array}$} & \multicolumn{5}{|c|}{ Samples $^{\mathrm{a}}$} \\
\hline & & & & & & $\mathrm{VV}$ & VV & FC & VA & $\mathrm{PB}$ \\
\hline 1 & ethyl acetate ${ }^{b}$ & - & - & $879^{\mathrm{d}}$ & $885[28]$ & $*$ & $*$ & $*$ & $*$ & $*$ \\
\hline 2 & ethyl propanoate ${ }^{\mathrm{b}}$ & $717^{\mathrm{d}}$ & 708 & $949^{\mathrm{d}}$ & $946[29]$ & $*$ & & $*$ & & \\
\hline 3 & ethyl butanoate ${ }^{\mathrm{b}}$ & $809^{\mathrm{d}}$ & 803 & 1037 & 1033 [29] & $*$ & & $*$ & $*$ & \\
\hline 4 & propanol $^{\mathrm{b}}$ & - & - & 1045 & $1046[26]$ & $*$ & & $*$ & $*$ & \\
\hline 5 & ethyl 2-methylbutanoate & $848^{\mathrm{d}}$ & 842 & 1050 & $1055[26]$ & $*$ & & & $*$ & \\
\hline 6 & ethyl isovalerate ${ }^{\mathrm{b}}$ & $855^{\mathrm{d}}$ & 850 & 1060 & $1061[26]$ & $*$ & & & $*$ & \\
\hline 7 & isoamyl acetate ${ }^{\mathrm{b}}$ & $879^{\mathrm{d}}$ & 873 & 1118 & $1123[26]$ & $*$ & & $*$ & $*$ & * \\
\hline 9 & isoamyl alcohol ${ }^{\mathrm{c}}$ & $719^{d}$ & 729 & 1220 & $1210[26]$ & $*$ & $*$ & $*$ & $*$ & $*$ \\
\hline 8 & ethyl hexanoate ${ }^{b}$ & 1001 & 1003 & 1222 & $1232[26]$ & $*$ & $*$ & $*$ & $*$ & $*$ \\
\hline 10 & isoamyl butanoate ${ }^{\mathrm{c}}$ & 1050 & 1057 & 1249 & $1255[27]$ & & & $*$ & $*$ & \\
\hline 11 & ethyl 2-hexenoate ${ }^{\mathrm{c}}$ & - & - & 1330 & $1336[26]$ & & & & $*$ & \\
\hline 12 & ethyl lactate ${ }^{\mathrm{b}}$ & $810^{\mathrm{d}}$ & 814 & 1348 & 1349 [26] & $*$ & $*$ & $*$ & $*$ & \\
\hline 13 & hexanol $^{\mathrm{b}}$ & $868^{\mathrm{d}}$ & 871 & 1355 & $1351[26]$ & $*$ & $*$ & $*$ & $*$ & $*$ \\
\hline 14 & ethyl octanoate ${ }^{\mathrm{b}}$ & 1206 & 1202 & 1441 & $1430[26]$ & $*$ & $*$ & $*$ & $*$ & $*$ \\
\hline 15 & acetic acid ${ }^{\mathrm{c}}$ & - & - & 1463 & 1452 [29] & $*$ & $*$ & $*$ & $*$ & * \\
\hline 16 & diethyl hidroxybutanoate ${ }^{\mathrm{b}}$ & $937^{\mathrm{d}}$ & 936 & 1520 & $1527[1]$ & & & $*$ & $*$ & $*$ \\
\hline 17 & ethyl nonanoate ${ }^{\mathrm{c}}$ & 1290 & 1297 & 1549 & $1581[28]$ & & $*$ & $*$ & & \\
\hline 18 & 2,3 butanediol $^{\mathrm{c}}$ & $780^{\mathrm{d}}$ & 789 & 1550 & 1545 [29] & $*$ & $*$ & $*$ & $*$ & $*$ \\
\hline 19 & diethyl malonate ${ }^{c}$ & 1271 & 1268 & 1587 & $1582[26]$ & $*$ & & & & \\
\hline 20 & ethyl decanoate ${ }^{\mathrm{c}}$ & 1398 & 1399 & 1635 & $1639[26]$ & $*$ & $*$ & $*$ & * & * \\
\hline 21 & isoamyl octanoate $\mathrm{c}^{\mathrm{c}}$ & 1441 & 1449 & 1644 & $1649[26]$ & $*$ & $*$ & $*$ & $*$ & $*$ \\
\hline 22 & diethyl succinate ${ }^{\mathrm{b}}$ & 1185 & 1183 & 1679 & $1678[26]$ & $*$ & $*$ & $*$ & $*$ & $*$ \\
\hline 23 & ethyl 9-decenoate ${ }^{\mathrm{c}}$ & - & - & 1694 & $1691[26]$ & $*$ & & & $*$ & \\
\hline 24 & phenylethyl acetate ${ }^{\mathrm{b}}$ & 1254 & 1257 & 1799 & $1795[26]$ & $*$ & & $*$ & $*$ & * \\
\hline 25 & ethyl dodecanoate ${ }^{\mathrm{c}}$ & 1597 & 1598 & 1832 & $1827[26]$ & $*$ & & $*$ & $*$ & $*$ \\
\hline 26 & hexanoic acid ${ }^{b}$ & - & - & 1883 & $1885[26]$ & & $*$ & & & \\
\hline 27 & 2-phenylethanol ${ }^{\mathrm{b}}$ & 1116 & 1113 & 1896 & $1888[26]$ & $*$ & $*$ & $*$ & $*$ & $*$ \\
\hline 28 & dodecanol $^{\mathrm{c}}$ & 1478 & 1476 & 1971 & $1981[28]$ & $*$ & $*$ & $*$ & $*$ & \\
\hline 29 & octanoic acid ${ }^{\mathrm{b}}$ & 1199 & 1192 & 2068 & $2072[1]$ & $*$ & $*$ & $*$ & $*$ & * \\
\hline 30 & nonanoic acid ${ }^{c}$ & 1278 & 1289 & 2168 & 2164 [30] & & $*$ & & & \\
\hline 31 & decanoic acid ${ }^{\mathrm{b}}$ & 1398 & 1399 & 2257 & $2261[1]$ & & $*$ & $*$ & & $*$ \\
\hline 32 & dodecanoic acid $^{\mathrm{b}}$ & 1569 & 1581 & 2509 & $2517[28]$ & $*$ & & $*$ & $*$ & $*$ \\
\hline
\end{tabular}

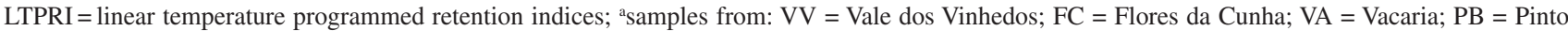
Bandeira; OV-5 = stands for a capillary column containing a methyl $5 \%$ and polysiloxane $95 \%$ stationary phase; Wax: stands for a capillary column containing a polyethylene glycol stationary phase; FFNSC = Flavor and Fragrance Natural and Synthetic Compounds Library, Shimadzu, Milan, Italy; $\mathrm{Lit}=$ data reported in scientific literature; ${ }^{\mathrm{b}}$ compounds positively identified through co-injection with standards; ${ }^{\mathrm{c}}$ tentatively identified compounds; ${ }^{\mathrm{d}} \mathrm{LTPRI}$ calculated through extrapolation. More details on procedure are referred to the Experimental session. * compounds that were detected and tentatively or positively identified in that specific base wine. 
were tentatively identified in the Chardonnay base wine samples of five different wineries of state of Rio Grande do Sul, Brazil. Experimental LTPRI values were in good agreement with literature data. ${ }^{1,26-30}$ The majority (56\%) of the compounds were esters, especially ethyl esters. Other minor components identified were alcohols and acids.

One of the most important groups of aroma compounds in base wines are the ethyl esters of fatty acids. They are produced during yeast fermentation through enzyme activity and during ethanolysis of acylcoenzyme (acylCoA), which was formed during fatty acids synthesis or degradation. The concentration of these esters depends on several main factors: yeast strain, fermentation temperature, aeration degree and sugar contents. ${ }^{31}$ Among the identified compounds, $48 \%$ were ethyl esters, which provide a positive contribution to the general quality of wine. They are responsible for the fruity and floral sensory properties of wine. Among the most important ethyl esters regarding wine aroma, found in the headspace of the investigated wines, the following should be mentioned: ethyl butanoate (strawberry, fruity), ethyl hexanoate (green apple, fruity), ethyl octanoate (pineapple, pear, floral), ethyl decanoate (fruity), ethyl lactate (raspberry) and diethyl succinate (floral). Phenethyl acetate and isoamyl acetate were also identified and they impart a floral and banana aroma, respectively. Acetate esters are the result of the reaction of acetyl-CoA with higher alcohols formed from degradation of amino acids or carbohydrates. ${ }^{32,33}$

The higher alcohols (i.e., of higher molecular weight than ethanol), also known as fusel alcohols, found in base wine samples were the aliphatic alcohols: propanol (bright flavor, alcohol), hexanol (green, grass), dodecanol (coconut, honey, earthy, fatty), 2,3 butanediol (chemical) and the aromatic 2-phenylethanol (roses, pollen, flowery). These compounds might have both positive and negative impacts on aroma. Hexanol, for example, is usually a minor constituent, but its herbaceous and greasy odors have been related to deleterious effects in wines, although consumers can appreciate a small herbaceous perception in some wines. Isoamyl alcohol, 2-phenylethanol and propanol were among the aromas released as secondary products of yeast metabolism. These compounds can be synthesized by yeast through either the anabolic pathway from glucose or catabolic pathway from their corresponding amino acids (leucine, iso-leucine and phenylalanine). ${ }^{28,34}$

Other important compounds of wine aroma are the fatty acids. Acetic acid, which is a by-product of fermentation, was found in all samples. The presence of this specific acid is very important as it is responsible for imparting a vinegar-like character to the wine. Other acids identified in the samples were octanoic, nonanoic, decanoic and dodecanoic, which also lend a bad effect to the overall wine aroma. ${ }^{25}$

Some esters, alcohols and acids were found in all samples such as ethyl acetate, ethyl hexanoate, ethyl octanoate, ethyl decanoate, diethyl succinate, isoamyl octanoate, isoamyl alcohol, hexanol, 2,3-butanediol, 2-phenylethanol, acid acetic and acid octanoic. However, ethyl 2-hexenoate, diethyl malonate, acid hexanoic and acid nonanoic seemed to be specific to some of studied samples.

\section{Cluster and sensory analysis}

Using Ward's method and Euclidean distances to measure the similarity between the base wines samples, two clusters can be viewed (Figure 5). The first group comprises samples from the Vale dos Vinhedos (VV) and Flores da Cunha (FC) regions and the second group is formed by samples from Vacaria (VA) and Pinto Bandeira (PB) regions. These results show similarities and dissimilarities among samples from these two groups. A careful analysis of experimental data shows that the amounts of ethyl decanoate, ethyl dodecanoate, phenylethyl acetate, octanoic acid and 2,3-butanediol differentiated the samples of the Vacaria and Pinto Bandeira regions from other samples. Among these compounds the only one that gives negative aroma to wine is the octanoic acid, which is responsible for the aroma of rotten fruit. Samples of the first group (Vale dos Vinhedos and Flores da Cunha) were differentiated by higher amounts of some ethyl esters especially ethyl acetate, ethyl hexanoate, ethyl octanoate and ethyl lactate. These esters contribute positively to wine aroma, attributing fruity characteristics to it. In addition, the lower scores for undesirable aroma were observed for Vale dos Vinhedos and Flores da Cunha samples (Table 6).

The sensory analysis of base wines was performed by evaluating their global organoleptic quality. The scores for

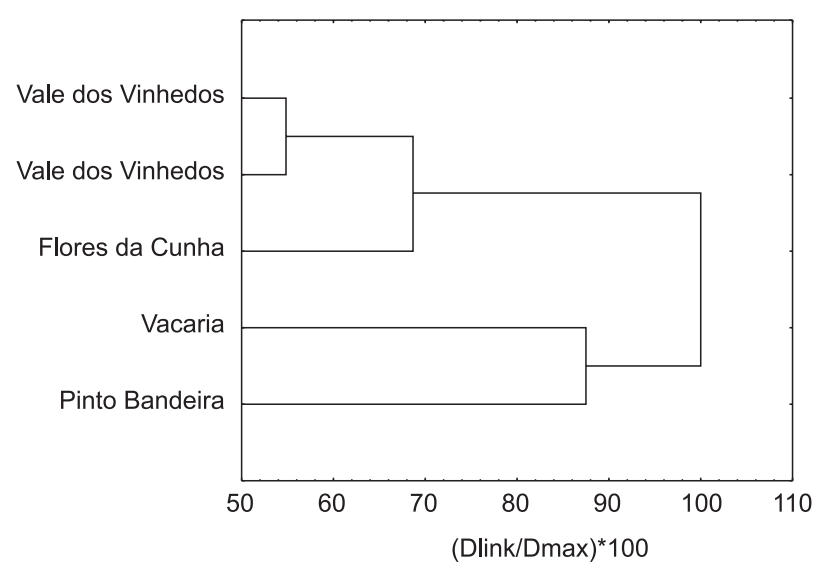

Figure 5. Dendrogram obtained for Chardonnay base wines of different regions of Serra Gaúcha using Ward's method and Euclidean distances. 
Table 6. Mean of sensory attributes (scale of 1-5) of Chardonnay base wines

\begin{tabular}{lccccc}
\hline \multirow{2}{*}{ Attribute } & \multicolumn{5}{c}{ Samples* } \\
\cline { 2 - 6 } & VA & VV & FC & PB & VV \\
\hline Visual assesment & & & & & \\
Color intensity & $2.9 \mathrm{a}$ & $2.9 \mathrm{a}$ & $2.3 \mathrm{~b}$ & $2.6 \mathrm{a}, \mathrm{c}$ & $2.8 \mathrm{a}, \mathrm{c}$ \\
Olfactory assessment & & & & & \\
$\quad$ Aroma intensity & $3.4 \mathrm{a}$ & $2.8 \mathrm{~b}$ & $2.8 \mathrm{~b}$ & $2.6 \mathrm{~b}$ & $2.9 \mathrm{~b}$ \\
Citric fruits & $1.9 \mathrm{a}$ & $2.4 \mathrm{~b}$ & $2.5 \mathrm{~b}$ & $2.4 \mathrm{~b}$ & $2.6 \mathrm{~b}$ \\
Tropical fruits note & $1.6 \mathrm{a}$ & $1.7 \mathrm{a}$ & $1.6 \mathrm{a}$ & $1.4 \mathrm{~b}$ & $1.8 \mathrm{a}, \mathrm{d}$ \\
Floral note & $1.3 \mathrm{a}$ & $1.3 \mathrm{a}$ & $1.9 \mathrm{~b}$ & $1.5 \mathrm{c}$ & $1.1 \mathrm{a}, \mathrm{d}$ \\
$\quad$ Herbaceous note & $1.1 \mathrm{a}$ & $0.9 \mathrm{a}$ & $0.4 \mathrm{~b}$ & $1.6 \mathrm{c}$ & $0.4 \mathrm{~b}, \mathrm{~d}$ \\
Undesirable aroma & $2.1 \mathrm{a}$ & $0.1 \mathrm{~b}$ & $0.0 \mathrm{~b}$ & $0.3 \mathrm{~b}$ & $0.1 \mathrm{~b}$ \\
Gustative assessment & & & & & \\
Paladar intensity & $3.6 \mathrm{a}$ & $3.0 \mathrm{~b}$ & $2.9 \mathrm{~b}$ & $2.8 \mathrm{~b}$ & $3.1 \mathrm{~b}$ \\
Body & $3.0 \mathrm{a}$ & $2.8 \mathrm{a}$ & $2.9 \mathrm{a}$ & $2.4 \mathrm{~b}$ & $3.0 \mathrm{a}, \mathrm{d}$ \\
Sweetness & $2.8 \mathrm{a}$ & $1.4 \mathrm{~b}$ & $1.8 \mathrm{c}$ & $1.3 \mathrm{~b}, \mathrm{~d}$ & $2.4 \mathrm{e}$ \\
Acidity & $2.5 \mathrm{a}$ & $3.6 \mathrm{~b}$ & $3.3 \mathrm{c}$ & $3.7 \mathrm{~b}, \mathrm{~d}$ & $3.1 \mathrm{e}$ \\
Astringency & $0.8 \mathrm{a}$ & $0.6 \mathrm{a}$ & $0.2 \mathrm{~b}$ & $0.6 \mathrm{a}, \mathrm{c}$ & $0.4 \mathrm{a}, \mathrm{b}$ \\
Bitterness & $1.1 \mathrm{a}$ & $0.3 \mathrm{~b}$ & $0.3 \mathrm{~b}$ & $0.4 \mathrm{~b}$ & $0.3 \mathrm{~b}$ \\
Persistence & $3.0 \mathrm{a}$ & $2.8 \mathrm{a}$ & $2.9 \mathrm{a}$ & $2.5 \mathrm{~b}$ & $3.2 \mathrm{a}, \mathrm{c}$ \\
\hline
\end{tabular}

*samples from: VA = Vacaria; $\mathrm{VV}=$ Vale dos Vinhedos; FC = Flores da Cunha; PB = Pinto Bandeira. Mean followed by same letter in a same line are not significantly different $(\mathrm{p}<0.05)$ by Tukey test.

the wines are displayed in Figure 6. Samples from Vale dos Vinhedos and Flores da Cunha showed the highest quality scores, while samples from Vacaria obtained the lowest rating. In addition, samples received the higher scores for herbaceous note and undesirable aroma, astringency and bitterness (Table 6). These sensory attributes negatively influence the wines.

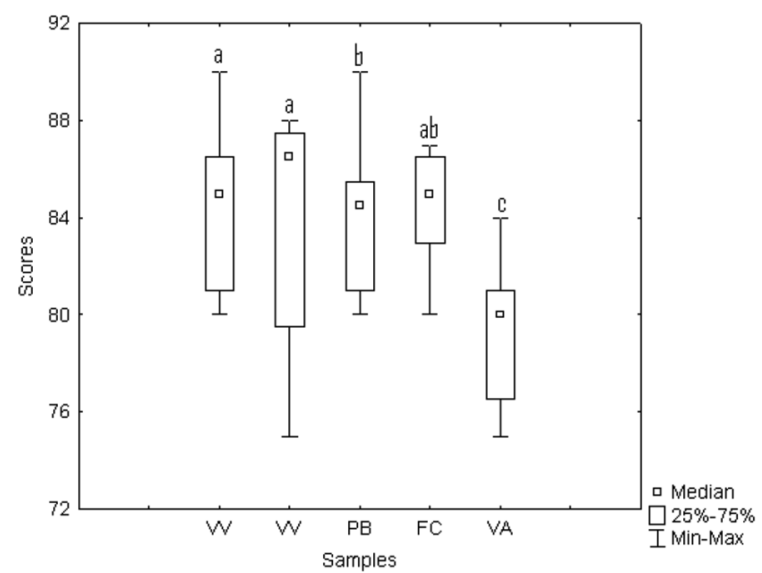

Figure 6. Sensory global evaluations of base wines produced in four different sub-regions of Serra evaluated by ANOVA and LSD test at $95 \%$ of significance. Different letters indicate significant differences among the samples.
Wines elaborated in Vale dos Vinhedos region stand out for their higher amounts of some ethyl esters responsible for fruity aroma such as ethyl acetate, ethyl hexanoate and ethyl octanoate. The Pinto Bandeira wine samples have high contents of ethyl decanoate, which contributes to its fruity aroma. Diethyl succinate, 2-phenylethanol and phenylethyl acetate were also found in this wine, both characterized by floral aroma. Wines from Vacaria were the least appreciated, probably because of their lowest concentrations of esters and higher concentrations of octanoic acid and isoamyl alcohol, which are characterized for their unpleasant aroma.

\section{Conclusions}

The aroma profile of base wines of Rio Grande do Sul state was, for the first time, successfully characterized by HS-SPME followed GC/MSD and GC-FID analysis. Among the identified compounds, $48 \%$ were ethyl esters, which provided a positive contribution to the general quality of wine. By means of cluster analysis, the differentiation among base wines produced in five different wineries of the South part of Brazil could be well established through particular aroma compounds identified in base wine samples. The higher chromatographic peak areas of ethyl acetate, ethyl hexanoate and ethyl octanoate were a main contribution for the differentiation of Vale dos Vinhedos samples from other base wine samples and for the highest quality scores in sensory analysis. Results of sensory analysis could be consistently related to the presence of compounds in wine aroma found through chromatographic analysis. In this way, the identification of volatile compounds of wines may contribute to the search for improvements in the production of grapes and wine processing.

\section{Acknowledgments}

The authors thank Conselho Nacional de Desenvolvimento Científico e Tecnológico (CNPq), Coordenação de Aperfeiçoamento de Pessoal de Nível Superior (CAPES), and Fundação de Amparo a Pesquisa do Estado do Rio Grande do Sul (FAPERGS) for financial support and scholarships. Leila Falcão is also especially acknowledged for contributing with standard compounds for this research project.

\section{References}

1. Boido, E.; Lloret,A.; Medina, K.; Farñia, L.; Carrau, F.; Versini, G.; Dellacassa, E.; J. Agric. Food Chem. 2003, 51, 5408.

2. Armanino, C.; Casolino, M. C.; Casale, M.; Forina, M.; Anal. Chim. Acta 2008, 614, 134. 
3. Koundouras, S.; Marinos, V.; Gkoulioti, A.; Kotseridis, Y.; Van Leeuwen, C.; J. Agric. Food Chem. 2006, 54, 5077.

4. Sabon, I.; Revel, G. D.; Kotseridis, Y.; Bertrand, A.; J. Agric. Food Chem. 2002, 50, 6341.

5. Torrens, J.; Riu-Aumatell, M.; López-Tamames, E.; Buxaderas, S.; J. Chromatogr. Sci. 2004, 42, 310.

6. Esti, M.; Tamborra, P.; Anal. Chim. Acta 2006, 563, 173.

7. Arthur, C.; Pawliszyn, J.; Anal. Chem. 1990, 62, 2145.

8. Kataoka, H.; Lord, H. L.; Pawliszyn, J.; J. Chromatogr., A 2000 , $880,35$.

9. Wardencki, W.; Michulec, M.; Curylo, J.; Int. J. Food Sci. Technol. 2004, 39, 703.

10. Câmara, J. C.; Alves, M. A.; Marques, J. C. Anal. Chim. Acta 2006, 555, 191.

11. Demyttenaere, J. C. R.; Dagher, C.; Sandra, P.; Kallithrak, S.; Verhé, R.; Kimpe, N.; J. Chromatogr., A 2003, 985, 233.

12. Rodrigues, F.; Caldeira, M.; Câmara, J. S.; Anal. Chim. Acta 2008, 609, 82 .

13. Risticevic, S.; Carasek, E.; Pawliszyn, J.; Anal. Chim. Acta 2008, 617, 72 .

14. Januszkiewicz, J.; Sabik, H.; Azarnia, S.; Lee, B.; J. Chromatogr., A 2008, 1195, 16.

15. Bogusz Junior, S.; de Melo, A. M. T.; Zini, C. A.; Godoy, H. T.; J. Chromatogr., A 2011, 1218, 3345.

16. Lawless, H. T.; Heymann, H.; Sensory Evaluation of Food. Principles and Practices; Kluwer, Academic/Plenum Publishers: Massachusetts, 1998.

17. Brereton, R. G.; Chemometrics: Data Analysis for the Laboratory and Chemical Plant; John Wiley \& Sons: Chichester, 2003.

18. Setkova, L.; Risticevic, S.; Pawliszyn, J.; J. Chromatogr., A 2007, 1147, 224.
19. Ceva-Antunes, P. M. N.; Bizzo, H. R.; Silva, A. S.; Carvalho, C. P. S.; Antunes, O. A. C.; LWT- Food Sci. Technol. 2006, 39, 436.

20. Rodríguez-Bencomo, J. J.; Conde, J. E.; Rodríguez-Delgado, M. A.; Garcia-Montelongo, F.; Pérez-Trujillo, J. P.; J. Chromatogr., A 2002, 963, 213.

21. Mestres, M.; Busto, O.; Guasch, J.; J. Chromatogr., A 1998, $808,211$.

22. Whiton, R. S.; Zoecklein, B. W.; Am. J. Enol. Vitic. 2000, 51, 379.

23. Câmara, J. S.; Alves, M. A.; Marques, J. C.; Anal. Chim. Acta 2006, 555, 191.

24. Carasek, E.; Pawliszyn, J.; J. Agric. Food Chem. 2006, $54,8688$.

25. Plutowska, B.; Wardencki, W.; Anal. Chim. Acta 2008, 613, 64.

26. Bosch-Fusté, J.; Riu-Aumatell, M.; Guadayol, J.M.; Caixach, J.; López-Tamames, E.; Buxaderas, S.; Food Chem. 2007, 105, 428.

27. Fang, Y.; Qian, M. C.; J. Agric. Food Chem. 2005, 54, 8567.

28. Li, H.; Tao, H. S.; Wang, H.; Zhang, L.; Eur. Food Res. Technol. 2008, 227, 287.

29. Gürbüz, O.; Rouseff, J. M.; Rouseff, R. L.; J. Agric. Food Chem. 2006, 54, 3990.

30. Verzera, A.; Ziino, M.; Condurso, C.; Romeo, V.; Zappala, M.; Anal. Bioanal. Chem. 2004, 380, 930.

31. Lee, S. J.; Rathbone, D.; Asimont, S.; Adden, R.; Ebeler, S. E.; Am. J. Enol. Vitic. 2004, 55, 346.

32. Etiévant, P. X. In Volatile Compounds in Foods and Beverages; Maarse, H., ed., Marcel Dekker: New York, 1991, ch. 14.

33. Vianna, E.; Ebeler, S. E.; J. Agric. Food Chem. 2001, 49, 589.

34. Perestrelo, R.; Fernandes, A.; Albuquerque, F. F.; Marques, J. C.; Camara, J. S.; Anal. Chim. Acta 2006, 563, 154.

Submitted: August 23, 2011

Published online: February 23, 2012 